\title{
A time to be born
}

Department of Obstetrics and Gynaecology, St George's Hospital Medical G V P Chamberlain, FRCOG, professor

M F Azam, student

Correspondence to: Professor Chamberlain. School, London SW17 ORE

\section{G V P Chamberlain, M F Azam}

One of us had a friend who was a shepherd in Gower. This shepherd had raised sheep for over 50 years and knew their gestational habits well. He used to claim that they rarely lambed at the time of the ebb tide but generally gave birth during the time of the flood. Most of Gower is close to the sea, and the times of high tides

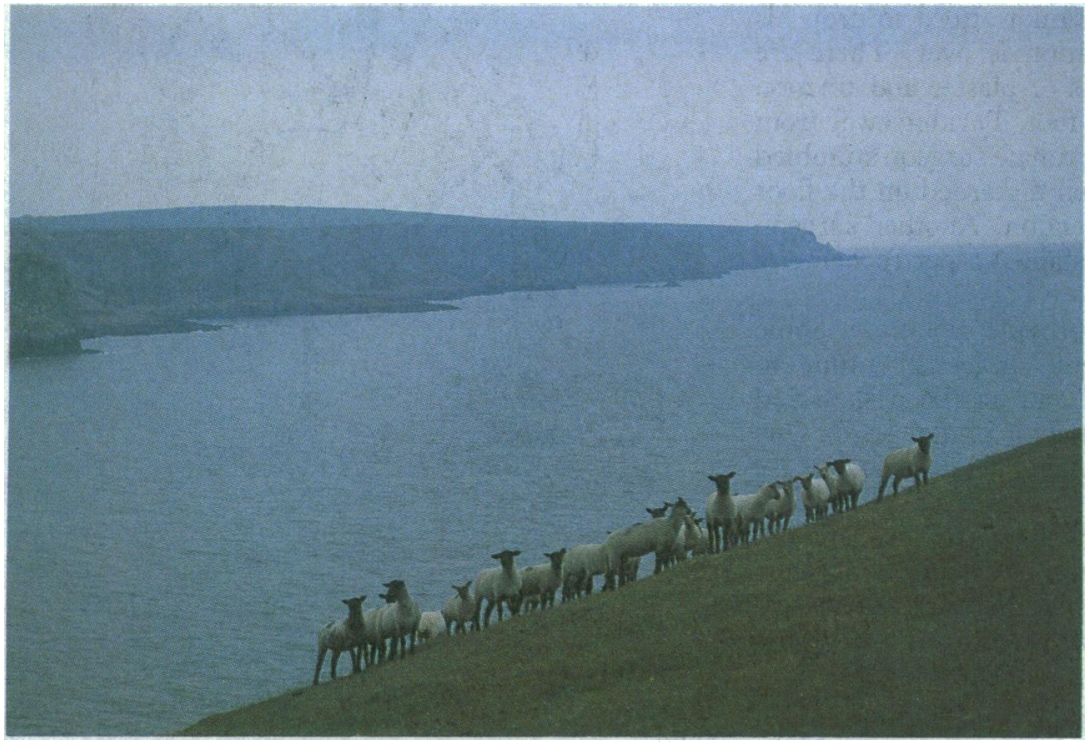

Sheep on headland, Rhossili, Gower were well known to shepherds and everyone else living there, for much depended on them. To test whether this phenomenon occurred in women we studied the population delivering at this hospital over two months, covering two lunar tidal cycles.

\section{Patients, methods, and results}

During July and August 1987, 471 women delivered spontaneously. Their labour was therefore considered to have started spontaneously and to have run its natural length. The time at which the women delivered was noted. The nearest recorded tidal point is Putney Bridge, which is $3 \mathrm{~km}$ from the hospital. A conversion to British summer time was needed as tide tables are recorded in Greenwich mean time.

The number of hours between the time of birth and the time of the closest flood tide was calculated and the women placed in groups of two hours. The table shows the results. There was no significant difference in the number of women delivering on the ebb and flood tides. Furthermore, there was no quantitative increase in relation to the flood tide.

Number of women giving birth in relation to time, of high tide

Time (h) from high tide: $\quad \begin{array}{llllll}-6 & -4 & -2 & +2 & +4 & +6\end{array}$ No of women: $\begin{array}{rrrrrr}-6 & -4 & -2 & +2 & +4 & +6 \\ 80 & 76 & 84 & 81 & 72 & 78\end{array}$

\section{Comment}

It seems that either our shepherd's memory is at fault or people do not behave like sheep.

We thank Deborah Everard for her help with the statistics.

\section{Orthopaedic surgery: a health hazard}

\section{J J Dias, I J Brenkel, S G Tordoff}

Department of Orthopaedic Surgery, Glenfield Hospital, Leicester

J J Dias, FRcs, lecturer in orthopaedic surgery

Department of Orthopaedic Surgery, Leeds Hospital, Leeds I J Brenkel, FRCSED, senior registrar in orthopaedic surgery

\section{Department of}

Anaesthetics, Poole

General Hospital, Dorset

S G Tordoff, MB, registrar in anaesthetics

Correspondence to: $\mathrm{Mr}$ Dias.
Since one of us (IJB) sustained an intraoperative injury ${ }^{1}$ we have heard of numerous injuries occurring during surgery. This led us to investigate further. We drew up a detailed form, and we posted just over 1000 of these forms to consultant orthopaedic surgeons in the United Kingdom (including retired consultants). We received 355 replies. It was clear from the replies that orthopaedic surgery can be extremely hazardous and nobody in the theatre is safe.

\section{Just a flesh wound}

Take for instance one surgeon's account of demonstrating the double cup hip operation to a senior colleague. Having made a sweeping incision, he held out the incision scalpel to the scrub nurse just as his colleague took his place by his side. The result was that he stabbed his colleague in the midriff, sinking the scalpel into his anterior abdominal wall. Fortunately, his colleague was well endowed in this area so there was no risk of peritonitis. As for the operation, it went well, although his colleague did keep his distance thereafter.

The combination of brute force and sharp instruments needed lays the orthopaedic surgeon open to painful and occasionally serious injury. Surgeons frequently skewer themselves or their assistants with Denham pins, and the number of surgeons who reported such mishaps was remarkable. The most extreme example was given by one consultant who, during the insertion of a Denham pin into a patient's leg, managed to transfix his assistant's hand and impale the patient's other leg, giving a whole new meaning to dynamic external fixation of fractures. The unfortunate assistant had to wait to be cut free.

We found that orthopaedic surgeons are at risk even during their training. One consultant recounted his unfortunate experience. While he was doing the lower end of an abdominoperineal resection the surgeon doing the upper end was a little overenthusiastic and cut off the tip of his right index finger.

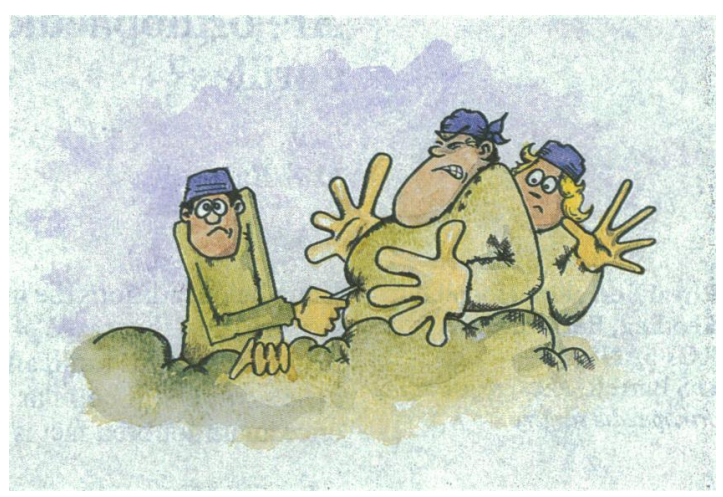

\section{Unexpected complications}

The surgeon, however, is not always to blame, and circumstances beyond his control can conspire to cause havoc. One respondent recounted that, "A certain surgeon was about to operate on a patient under a spinal anaesthetic when suddenly a mouse ran across the floor of the theatre, causing consternation and terror among the nursing staff. Its whereabouts were 
unknown until suddenly the patient sat up and, pointing at the mouse, shouted triumphantly, 'There it is!' Order having been restored by catching the mouse, the surgeon advanced once more towards the operating table. In doing so he struck his head violently against the rim of the operating lamp, not noticing that it had been placed somewhat lower than usual. He collapsed on to the floor, briefly concussed, and the patient sat up again, gazing in bewilderment at the dead mouse and the unconscious surgeon!"

\section{Postoperative risks}

An orthopaedic surgeon cannot afford to drop his guard even when the operation is over. There are numerous reports of buckets of plaster and traction weights crushing a surgeon's foot. Turning away from the operating table, one unfortunate surgeon stumbled on green towels that had been discarded on the floor and ruptured his Achilles tendon. Another surgeon tripped on the stairs and sustained a pertrochanteric fracture.

Even the home does not provide sanctuary. Some keen do it yourself orthopaedic surgeons continue to injure themselves. Many a hand has been skewered with a screwdriver or sliced with a Stanley knife. One surgeon sustained a mallet finger while rescuing his "psychopathic" dog from a fight. Another orthopaedic surgeon even found that getting away from it all did not ensure safety. While sailing in the West Indies his wife landed a barracuda over $1 \mathrm{~m}$ long. He was still trying to kill it with a blunt instrument when it bit him on the

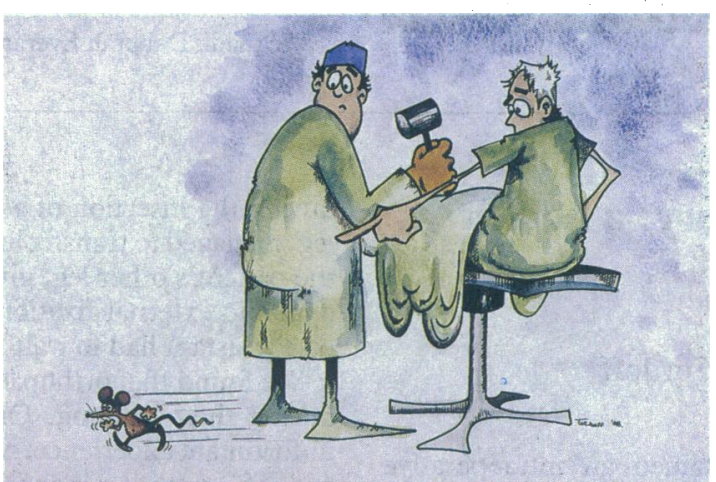

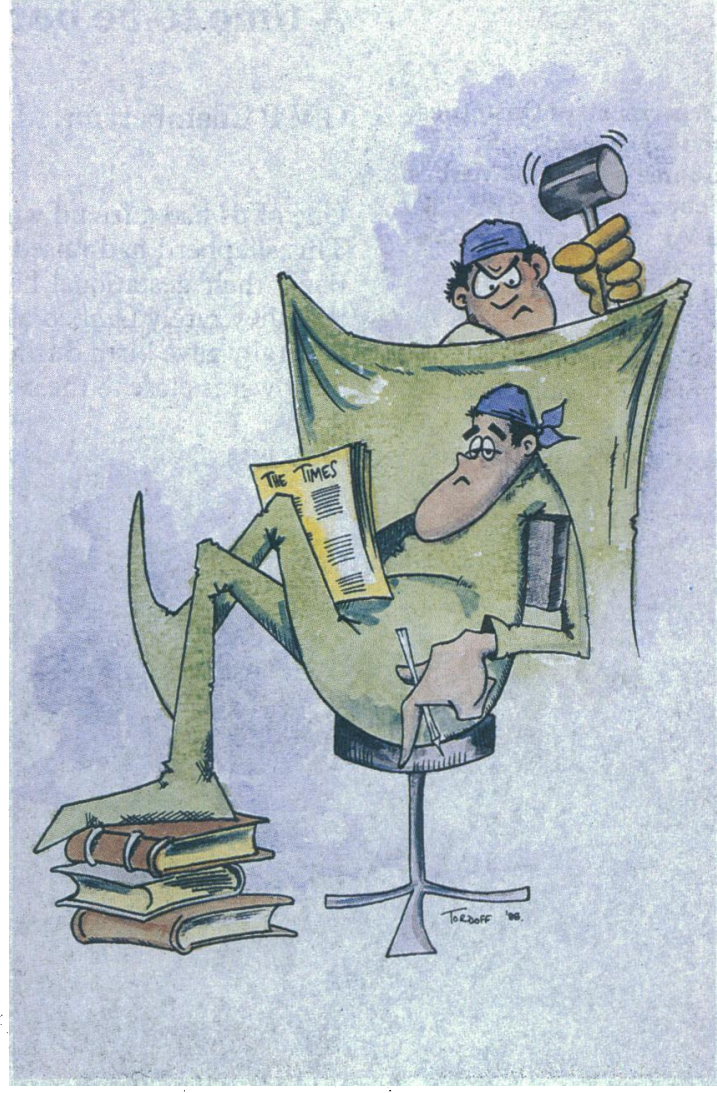

finger, severing the extensor tendon of his right ring finger.

We conclude that there are three ways for orthopaedic surgeons to avoid injury. Firstly, they could follow the example of one surgeon, who after repeated minor injuries bought himself a pair of glasses. Secondly, they could act on the advice of an eminent spinal surgeon from Stoke on Trent, who suggests that they get their assistant to do the dangerous work. Finally, if all else fails, they could become anaesthetists: there are no reports of injuries to doctors while doing The Times crossword puzzle.

1 Brenkel IJ, Pearce M, Gregg PJ. A cracking complication of hemiarthroplasty of the hip. BrMed F 1986;293:1648.

\section{Are orthopaedic surgeons gorillas?}

\section{S Barrett}

Royal Berkshire Hospital, Reading, Berkshire RG1 5AN

D S Barrett, FRCS, registrar in orthopaedic surgery
Long held traditions die hard in the specialty of general surgery, and the image of the orthopaedic surgeon as a man of enormous build and great strength, if perhaps a little slow, is still popular. I assessed whether what was once an undoubted fact is true today.

\section{Methods and results}

Hand size is closely related to body size and bulk. ${ }^{1}$ I established the size of gloves worn by a sample of orthopaedic and general surgeons by sending questionnaires to the theatre sisters of the departments of orthopaedics and general surgery in 30 hospitals selected at random throughout the United Kingdom. Twenty two of the 30 sisters (74\%) responded, giving the glove sizes of 166 general surgeons and 150 orthopaedic surgeons. When the surgeons wore two pairs of gloves only the size of the inner glove was used.

The mean size of glove worn by orthopaedic surgeons was 7.6 (SD 0.4) while the mean size of gloves worn by general surgeons was $7 \cdot 4(0 \cdot 4)$. The difference between the two groups was highly significant $(\mathrm{p}<0.001$, Student's $t$ test). The range in size for both groups was 8.5 to 6.0 . Standard techniques for assessing height from hand size ${ }^{2}$ showed that the orthopaedic surgeons were slightly taller than their general surgical colleagues (by $2 \cdot 3 \mathrm{~cm}$ ).

\section{Comment}

This method of measuring hand size has many disadvantages as the tightness of the glove varies among surgeons and the glove selected does not show the relative proportions of the hand, which represent a more sensitive anthropological indicator. In addition, glove size is not a continuous variable as it increases in fixed half sizes, and this limits the accuracy of the assessment. With a sufficiently large sample, however, this method gives an overview of the difference in hand size between the two groups. 